\title{
LAS PALABRAS Y LOS DÍAS EL DIARIO COMO FORMA LITERARIA ${ }^{1}$
}

\section{Antoni MARTí MONTERDE}

Universitat de Barcelona

oda definición busca concretarse, toda tentativa de definir la literatura, por tanto, resultará
paradójica; en la concreción actuará de manera inversa a su ser, al delimitar hacia la síntesis
lo que por naturaleza es infinito: un uso del lenguaje. Quizá por ello a menudo los intentos de definición de la literatura acaban por intensificar una única palabra con la esperanza de llegar a sugerir que contiene todo lo que la literatura es, proponiéndola como sinónima, sugiriendo que si no contiene la literatura definida, al menos sí lo que es la literatura. Así, sin embargo, se multiplica abismadamente su infinitud; pero al menos no se ha hecho crecer un abismo, aunque quizá se haya abierto otro.

Una de estas palabras que suelen proponerse como epicentro de una definibilidad de literatura es soledad. Escribir es soledad. O, como afirmaba María Zambrano en 1934, «escribir es defender la soledad en que se está» (1987: 31). Años más tarde, en 1955 Maurice Blanchot parece retomar esta idea, al afirmar que la soledad de la escritura no es una soledad mundana, ni siquiera la soledad del artista apartado, planteada más bien como un recogimiento productivo. La soledad del escritor es simétrica a la soledad de la obra. Se trata de una soledad esencial, y quien escribe pertenece al riesgo de esta soledad (1955: 16). El escritor defiende su soledad, según Zambrano, mostrando lo que en ella y solamente en ella encuentra. Parece ser que, para un escritor, estar solo no es suficiente, que la soledad ya tendría que ser un verbo, y no un sustantivo.

Pero en este punto se superponen otros esfuerzos de definición de la literatura, como los que se realizan desde la teoría de los géneros, implicando ciertas coincidencias con los planteamientos generales de Zambrano y Blanchot, pero concretados a determinadas formas de escritura. La escritura de los diarios plantea una de estas superposiciones significativas. La moderna escritura diarística ha sido definida recurrentemente como un repliegue hacia el interior que, al poner entre paréntesis el

\footnotetext{
${ }^{1}$ Recupero para este homenaje a Enric Sullà una ponencia leída en el Coloquio Internacional La crítica al final del milenio (Buenos Aires, Facultad de Filosofía y Letras-Biblioteca del Senado, agosto de 1998). Redactada de forma esquemática en Buenos Aires, el texto definitivo se redactó en 1999, cuando Enric Sullà y yo compartíamos despacho en la Universitat Autònoma de Barcelona. Con este rescate de viejos papeles intento rescatar también el excepcional ambiente intelectual y humano de que pude disfrutar en aquel despacho - al cual poco después se sumaría de manera efímera Salvador Companyentre 1997 y 2000.
} 
exterior, posibilitaría una especie de paraíso artificial. En palabras de Béatrice Didier, el diarista es un hombre de soledad: la busca en la naturaleza, en el seno mismo de la sociedad. La soledad crea un aire de silencio y de libertad donde el yo podrá verdaderamente existir (1976: 88). Nos encontramos con que hay una modalidad de escritura cuyo rasgo distintivo parece ser, precisamente, efectivamente, la soledad: «Estoy solo, y por eso existo más», escribió en su diario de 1956 Witold Gombrowicz (1999: 338).

Entonces, qué significa estar solo, si el escritor no es libre de estar solo sin expresar que lo está (Blanchot, 1977: 8), si esta soledad le define, desde dentro y desde fuera. Si la condición y límite de toda escritura es la soledad, la soledad de un escritor de diarios ha de resultar diferente. Estructuralmente diferente, funcionalmente diferente, incluso. Podríamos hablar de una doble soledad del escritor de diarios, pero sería inexacto, porque la soledad es indivisible, ingeminable, en tanto que inherente al individuo, aunque sea ondulante y diversa como él. Hay que mirar a la intimidad de la soledad.

Esta intimidad de la soledad es lo que permite abrir un espacio entre vida y escritura, superpuesto a otro espacio fronterizo entre vida y escritura creado en el mismo gesto, porque al fin y al cabo se trata del mismo espacio, considerado desde dos perspectivas. Es un espacio creado por la escritura misma: por su necesidad, y por su realización. Un espacio creado por la escritura mientras se halla a punto de constituirse, pero que se construye en aquel instante en que la escritura está a punto de olvidarse, en la inminencia de ser obra. En este frágil tiempo, la soledad del escritor de diarios se hace firme. Como la araña que escribe su hambre, el diarista escribe su soledad.

Para el escritor de diarios, la soledad es sólida.

La solidez de la soledad se afirma cuando todo aquello que le rodea pierde solidez, pero se hace contundente. Los orígenes formales del diario íntimo están anclados en el siglo XVIII, en una época determinada por transformaciones extraordinarias dentro de la sociedad occidental. Por eso se consolida como forma de expresión durante el siglo XIX, que intensifica estas transformaciones, y llega a su momento álgido hacia comienzos del siglo XX, cuando estas transformaciones se vuelven febriles. Por tanto, el diario íntimo se desarrolla simultáneamente a la tensión entre modernidad y progreso.

Baudelaire, en 1863, en El pintor de la vida moderna, definía el individuo moderno como un observador apasionado que ubicaba su residencia en lo ondulante, en el movimiento, en lo huidizo y fugaz, en lo infinito. Consideraba el individuo moderno como un «enamorado de la vida universal [que] entra en la multitud como en un inmenso depósito de electricidad. También se le puede comparar, a él, a un espejo tan inmenso como la multitud; a un calidoscopio dotado de consciencia, que, a cada uno de sus movimientos, representa la vida múltiple y la gracia moviente de todos los elementos de la vida. Es un yo insaciable de no yo [...]». Solitario dotado de una imaginación activa, errante en este desierto de hombres, inconfundible con el mero paseante y su circunstancia limitada, destrozando y recomponiendo como calidoscopio que a cada movimiento cambiase de manera incesante la forma cortante de los fragmentos del espejo que Stendhal había tomado prestado a Saint-Réal, y con ellos «busca algo que se nos permitirá llamar la modernidad» (Baudelaire, 1996: 358-361). Pero este 
legítimo entusiasmo por la complejidad de la vida moderna bien pronto se mostraría como conciencia de una situación desbordante. El mismo Baudelaire tenía muy clara la distinción entre modernidad y progreso: sospechaba ya en el año 1855, en su «Método de la crítica. De la idea moderna de progreso aplicada a las bellas artes. Desplazamiento de la vitalidad», que el progreso era un error fundamental del cual era necesario protegerse como del infierno. Para Baudelaire, la idea de progreso no era sino un «fanal oscuro, invención del filosofismo actual, patentado sin garantía de la Naturaleza o de la Divinidad» una «linterna moderna que arroja tinieblas sobre los objetos del conocimiento». Pueden sorprender estas observaciones de Baudelaire, pero no cabe duda de que no entran en contradicción con su idea de la modernidad, puesto que el centro de sus preocupaciones es el mismo: la posición del individuo en un nuevo tiempo, transformado en época, en que «la libertad se desvanece, el castigo desaparece. [...] Esta idea grotesca, que ha florecido en el podrido terreno de la fatuidad moderna, ha descargado a todos de su deber, liberado a cada alma de su responsabilidad, liberado a la voluntad de todos los vínculos que le imponía el amor a lo bello. [...] Dejo de lado la cuestión de saber si, fragilizando a la humanidad en proporción a los nuevos goces que le aporta, el progreso indefinido no sería su más ingeniosa y cruel tortura; si, procediendo por una porfiada negación de sí mismo, no sería un modo de suicidio incesantemente renovado» (1996: 203-204). El progreso, pues, sería una absurdez, ofrecería su faz grotesca, que roza lo espantoso, como reflejo de una eterna desesperación cuyos hechos, dice -recordemos, en 1855-, ya son palpables. Baudelaire entrevé la noción de progreso como paralizadora del individuo, en virtud de la preeminencia que la vida práctica había alcanzado por encima de la vida del espíritu. Temía que la espiral que entrelazaba la modernidad a la ciencia y la técnica acabase por hacer olvidadizo que el individuo era el protagonista de su tiempo. No se equivocaba. Años más tarde ya resulta una evidencia que el hombre había quedado desbordado por sus maquinaciones, entre las cuales la economía, también prevista por el autor de Las Flores del Mal, no era la menos importante. Finalmente, el progreso de signo utilitarista cada vez se vincularía más estrechamente con la violencia. El tiempo originario del diario íntimo es, así pues, un tiempo de transformaciones, un tiempo de crisis. El diario llega a su esplendor en un instante que le obliga a definirse y a decidirse: se convierte, de manera redundante, en la forma de expresión de momentos de crisis y transformación. Si el individuo se interroga con tanta avidez sobre sí mismo es porque su situación se tambalea y necesita encontrar cimientos para un nuevo equilibrio, afirma razonablemente Girard (1963: 35). El individuo trata de resguardar su consistencia, o construirla, ante un mundo que cada vez tiene menos, pero que cuanta menos consistencia parece tener, más peso, más contundencia adquiere sobre el individuo.

Aun así, quizá los argumentos de Girard y Didier se ven desbordados por sus propias referencias al adentrarse en el siglo XX. Este desbordamiento se debe, fundamentalmente, a dos razones: la irrenunciable y definitiva toma de conciencia por parte del individuo de haber dejado de ser la medida de todas las cosas y la nueva posición del individuo respecto a la escritura y la literatura.

La individualidad es el gran problema del individuo. Como afirma Georg Simmel hacia 1913, «a través de toda la modernidad la búsqueda del individuo va hacia sí mismo, hacia un punto de solidez 
y carácter inequívoco, el cual se necesitaba tanto más urgentemente debido al inaudito ensanchamiento de la perspectiva teórica y práctica y a la complicación de la vida, y que precisamente por esto ya no podía ser encontrado en ninguna instancia externa al alma»(1986: 276). Simmel describe de esta manera el proceso por el cual, desde el Romanticismo, las esperanzas de la individualidad se dirigen hacia la constitución misma de la subjetividad. De hecho cabe señalar que la escritura del yo no hace sino cambiar de definición a lo largo del tiempo, al menos desde Michel de Montaigne. Más todavía, Michel Foucault incluso se remite a la cultura grecolatina para situar el origen de lo que llama las artes del soi-même. De la mano de Plutarco, Foucault otorga a la escritura meditativa una función ethopoética que posibilitaría la transformación de la verdad en ethos (Foucault, 1985: 6), al tiempo que considera la escritura fundamental en el cuidado de sí: una cambiante preocupación de sí que implica una nueva experiencia del yo (1990: 62-63) que en los siglos I y II de nuestra era, por ejemplo en Séneca, plantea ya el cuidado de sí como una nítida autofinalidad (1994: 67-69). Con todo, el vínculo de estas transformaciones con la noción de crisis y con la confianza y esperanza depositada en el lenguaje en su relación con el paso de los días permite pensar en Montaigne como la encrucijada que recogería y modificaría radicalmente, a finales del siglo XVI, los ejemplos foucaultianos de la época clásica, y los desarrollaría no solo en lo que respecta al ensayo, sino también a la idea de escritura diaria, comenzando por la idea de repliegue sobre sí mismo, esencial en el diario. Montaigne modifica definitivamente la relación entre las palabras: «Al modelar mi propia figura, tanto he tenido que medirme y probarme para extractar mi esencia, que el patrón en algún modo se ha formado a sí mismo, pintándome a mí mismo con colores más rotundos que los míos primeros. Tanto he hecho yo a mi libro como mi libro me ha hecho a mí. Es obra consubstancial a su autor, ocupación propia y miembro integrante de mi vida» (Montaigne, 1991: 573) y los días: «el mundo es movimiento perenne y todo muda sin cesar [...] La misma constancia sólo es una mutación menos viva que la inquietud. No puedo asegurar mi objeto, porque se tambalea y turba como por embriaguez natural. Tómolo en el punto en que lo examino y no pinto su ser, sino el que me muestra al pasar, y no en un tránsito de una edad a otra, o, como dice el pueblo, de siete en siete años, sino de día en día y de minuto en minuto» (Montaigne, 1991: 683-684). El hecho de haber fundado el ensayo moderno ha eclipsado la figura de Montaigne como precursor, si no fundador también, del moderno diarismo.

Lo que Simmel registra es la exacerbación de ese proceso y las nuevas e hirientes circunstancias en que se da cuando, contradiciendo el calendario, está a punto de comenzar verdaderamente el siglo XX, en un conglomerado de instantes incendiados entre 1914 y 1918, culminación de la última fase de este proceso. Unos años antes, para explicar el contraste entre individuo y realidad como fricción, Simmel describe el surgimiento de una limitación entre los seres humanos que, por otro lado, sería lo único que haría posible la forma contemporánea de vida; se trata de una especie de distanciamiento sin el cual resultaría insoportable la promiscuidad y mezcolanza diversa de la circulación en las grandes ciudades, puesto que «el hecho de que el ser humano haya de habérselas con un número tan enorme de personas, como sucede en las relaciones comerciales, profesionales y sociales de la cultura urbana moderna, haría que los hombres modernos, sensible y nerviosos, cayeran en la desesperación, si 
aquella objetivación del carácter de la circulación no trajera consigo una frontera y una reserva interiores» (Simmel, 1977: 602-603). Por tanto, la desmedida realidad que había dado origen a la generalización de los diarios íntimos ya se ha convertido, a comienzos de siglo, en la única realidad del individuo, al menos en el ámbito urbano, que además crecía en proporción de forma exponencial, y determinaba cada vez más claramente las reglas mundanas en términos económicos. Todo cuanto en otro tiempo era exageración, se había vuelto verosímil, o cotidiano. La crisis ya no se asocia más a un momento de transición, sino que se vive en permanente crisis, en transición y mutación perpetua que las inflexiones de la historia de la barbarie jalonan brutalmente. Pero la crisis, la transformación constante, la tierra movediza, la metamorfosis del individuo, la velocidad inaprensible, el vértigo, son ya la única tierra firme de un náufrago. Y si los argumentos de Simmel son válidos para 1900, no lo son menos para nuestros días.

De la aceptación de estas coordenadas epocales ineludibles, de este malestar contemporáneo, surge el apartamiento y la reserva como medios de salvar la libertad o los fragmentos de libertad individual, pero esta libertad ya se encuentra acompañada por la soledad, a la que Béjar (1989: 55) añade de forma explícita el abandono. Si bien el individuo se encuentra en una situación de raíz romántica que le impulsa a escribir, ya no se halla en una situación como la de Robinson Crusoe que empuje a través de la escritura diaria hacia la conciencia del individualismo en la soledad. Ahora se trata de la soledad en sociedad; el abandono se ha hecho ubicuo, el naufragio itinerante y discontinuo, la presión de lo desconocido cercano, inminente, contigua, los espacios de repliegue móviles, errantes, atravesados en un caminar incesante.

De la evolución de este espacio de reserva surge una redefinición de la soledad, que ha de relacionarse con su enunciación, es decir, con el lenguaje que la expresa. En este sentido, el diario íntimo no puede sino hacerse literario, sin dejar de ser íntimo, o transformando esta condición también desde dentro del lenguaje. «Refugiados en su soledad, resultan sitiados por ella», concluye Puértolas (1989: 148). Y este asedio tiene lugar en la escritura, en un pliegue del refugio, en una distancia interior de la literatura. Si pensamos en este refugio como una forma de desplazamiento discontinuo, provisorio, itinerante, pero irrenunciable, podríamos pensar que el escritor mantiene con su soledad la misma relación que María Zambrano proponía en uno de los primeros artículos que publicó poco después de su regreso a España, el 28 de agosto de 1989, bajo el título «Amo mi exilio»: «El exilio ha sido como mi patria, o como una dimensión de una patria desconocida, pero que una vez que se conoce, es irrenunciable. [...] Creo que el exilio es una dimensión esencial de la existencia humana, pero al decirlo me quemo los labios, porque yo querría que no volviese a haber exiliados, sino que todos fueran seres humanos y a la par cósmicos, que no se conociera el exilio. Es una contradicción, qué le voy a hacer: amo mi exilio, será porque no lo busqué, porque no fui persiguiéndolo. No, lo acepté; y cuando se acepta algo de corazón, porque sí, cuesta mucho trabajo renunciar a ello» (Zambrano, 1955: 14). De la misma manera que al exiliado nadie le puede devolver los años de exilio, el escritor de diarios sabe que nadie le podrá devolver el tiempo pasado en soledad: pero ambos saben que tampoco nadie se los podrá quitar. Y en la soledad mundana descubre aspectos del mundo que permanecían invisibles hasta 
su autopercepción como individuo solitario. El escritor de diarios estima, ama su soledad, irrenunciable.

Si la literatura es una violencia ejercida sobre el lenguaje, es en tanto que violencia que mejor puede responder a la crisis que envuelve al escritor. Una vez creado el espacio de reserva interior, la literatura consigue dotarlo de consistencia. Pero es una consistencia que, al concretarse, se transforma en contundencia: «cuando se hace de noche y retomo el diario es para tenérmelas siempre contra mí mismo», anotó Foix en su Catalans de 1918 (1990: 233). Se trata de un espacio de reserva hacia lo privado, hacia lo secreto, en busca de la intimidad que requiere hacerse expresable. Y la crisis que empuja al escritor a escribir se encuentra dentro de sí. Interiorizada, la crisis cultural se hace crisis personal. El espacio de repliegue será también espacio de desvelamiento de sí definitivo, que de ninguna manera debe considerarse fácil. Una vez traspasado este límite, toda distancia se vuelve infinita, todo retorno imposible.

El diarista cuenta con una distancia que construye la escritura con el vértigo que la hace necesaria. De aquí que la soledad del diario sea una soledad multitudinaria, soledad sin apartamiento, insaciable de no yo. El diario, como escritura errante, como forma y acción, es la única escritura capaz de acompañar al escritor en su errancia a través del mundo que le empuja a escribir. La paradoja de la soledad multitudinaria que el diario escribe y describe en tiempo y espacio reales es una paradoja transformadora de ese espacio y ese tiempo. La intervención en la escritura en la vida a través del diario es performativa, visceral ${ }^{2}$.

Además, en este punto no encontramos con una seria duda, que señala Josep Pla: «¿es posible la expresión de la intimidad? Quiero decir la expresión clara, coherente, inteligible, de la intimidad. La intimidad pura, bien pensado, debe ser la espontaneidad pura, o sea una secreción visceral e inconexa. Si uno dispusiera de un lenguaje y de un léxico eficaces para presentar esta secreción, no habría problemas. Pero lo cierto es que no existe un estilo adecuado a la sinceridad ni un léxico eficiente. Pero aun suponiendo por un momento que la intimidad fuese expresable, ¿quién la entendería, quién la podría comprender? Si no fuese única, particularista, personalísima, absolutamente primigenia ¿qué aspecto tendría, cómo se podría imaginar su presencia? [...] Mi idea, pues, es que la intimidad es inexpresable por falta de instrumentos de expresión, que su proyección exterior es prácticamente informulable» (Pla, 2001: 186). Si lo íntimo es aquello que tienen de incomunicable la existencia y la experiencia individuales, el lenguaje con que se expresa lo íntimo ha de ser de su misma naturaleza; por tanto, como señala Marí, el acto de expresar la intimidad resulta una manera de explorarla, y esta exploración no cuenta con leyes, ni normas, ni preceptos con la ayuda de los cuales se pueda alcanzar la forma expresiva (Marí, 1995: 127-128). Pero, además, debe sumarse a todo ello la acción desfiguradora del lenguaje, que Pla pone como ejemplo de su razonamiento -todavía no de forma

\footnotetext{
${ }^{2}$ Releo estas notas en un café, poco antes de ir a leerlas en el congreso. Aparto la mirada del papel y la levanto hacia las mesas de alrededor. En una, cerca de la ventana, descubro a un joven que, con un bolígrafo en la mano, con papeles bajo los codos, observa la gente pasar al otro lado del cristal. De repente, vuelve la mirada a los folios y anota algo. ¿Qué estará escribiendo? ¿Qué está escribiendo, precisamente ahora? Ahora. Repliego mi mirada hacia mis papeles y descubro una mancha de café nublando esta palabra. ¿Cómo transcribiré esta mancha de café en la redacción definitiva?
} 
explícita relacionándola con la autobiografía y su doble sujeto, pero en las mismas páginas de $E l$ quadern gris, por tanto, en pleno esfuerzo diarístico y memorialístico-: «Pensad, solamente, en la enorme fuerza de deformación y de falsificación que tiene el estilo tradicional, la ortografía y la sintaxis habitual, en toda tentativa de querer expresar el pensamiento de apariencia más sencilla, en la pretensión de describir el objeto más insignificante» (Pla, 2001: 186).

Llevar esta expresión a la literatura no la dota de ninguna herramienta o recurso concretos, pero sí abre el abanico de itinerarios de exploración, partiendo de la idea de que no hay nada más íntimo que la necesidad de escribir, que la tensión que se desata en la voluntad de escribir y de hacerlo de manera decididamente literaria. La crisis de lenguaje y la tentación de silencio que cierra el siglo XIX y abre el XX como desconfianza encuentra en la literatura su último alivio. El esfuerzo que se trama en un diario por preservar, restituir, anhelar o construir, inventar o añorar la integridad del individuo, al vincularse a la intimidad se vincula a lo que Barthes (1992: 366-367) ha llamado un imaginario de segundo grado. En el diario, el escritor y la obra se persiguen, y la única manera de hacer cristalizar esta persecución es concebirla como un acto literario. Como lo hace Barthes, esto quizá implica considerar el diario como literario en el sentido más nostálgico del término, con un estatuto literario huidizo. Pero al menos es una distancia que, al volverse activa, al pasar de la imaginación al papel, recoge para la escritura del presente la lección proustiana: la vida, la única vida por fin descubierta y esclarecida, es la literatura (Proust, 1990: 201).

Pero el esclarecimiento de la vida en el diario como forma literaria hace pensar que los argumentos de Paul de Man (1984) sobre la autobiografía como desfiguración quizá son mucho más adecuados para pensar el diario literario que el resto de las escrituras autobiográficas. Si la escritura autobiográfica requiere un tiempo de desfiguración, si de hecho, es ese mismo tiempo de desfiguración, la escritura de los diarios es ese instante, el lapso y trance, el espacio de esta desfiguración. Precisamente porque, hecha de tiempo, no tiene tiempo para la desfiguración, le ofrece todo su espacio. Porque se trata de una desfiguración marcada no por aquello que el escritor imagina que fue, sino por aquello que está a punto de ser, y que será, en definitiva, en el acto de escribir. Si en la autobiografía, lo que uno fue es recuperado desde lo que uno es en el aquí y ahora de la autobiografía, lo que permite recordar lo que no se fue nunca, no sólo como si se hubiese sido (y como si se hubiese ido); esto caracteriza según Starobinski el estilo del presente como estilo de la autobiografía (Starobisnki, 1974: 66-70), en tanto que autointerpretación, autoinvención. Literariamente, ficción de sí, ficción hermenéutica, es lo que escribe el diarista. Y precisamente por eso, en tanto que ficción autobiográfica, se radicaliza en la escritura de diarios el estilo del presente. Si el estilo perturba el mensaje autobiográfico, si lo constituye, si modifica la conciencia de sí en proceso y, al mismo tiempo, modifica el presente en que se produce, la escritura del diario implica un pliegue en la realidad del escritor que afecta a su palabra, a su voz, entendida como su vida.

En este punto cabría distinguir, dentro de la tradición literaria diarística, los diarios propiamente dichos y aquellos que, en realidad, son como memorias nocturnas del día; los nocturnarios de un vivisector, como sugería Musil que eran los suyos, retomando una idea de Nietzsche. Estos diarios de 
noche se redactan principalmente en el intervalo reflexivo entre jornada y jornada, marcando un punto de inflexión que borrarían las noches en blanco, pero donde quedaría un hiato como marca de escritura, ya que transforma el pretérito perfecto que suele dominar sus enunciados en una forma verbal que se desplaza hacia el presente por efecto del devenir en la escritura, que como construcción de sentido y compre(he)nsión de la propia vida, puede ser mucho más profundo que el acontecer de los hechos mismos. En este sentido cabría también valorar la cuestión de la reescritura de los diarios, vinculada sobre todo a la voluntad de publicación. Esta reescritura sería una prueba más de la conciencia literaria del escritor, ya que solo se da a partir de la inscripción en el género literario y la vinculación con éste de la figura del hombre de letras como figura pública. Girard distingue tres épocas en la relación de los diarios con el público: de 1800 a 1860, los autores escriben para sí mismos; de 1860 a 1910 aparecen publicados los primeros diarios, pero póstumamente; desde 1910 se generaliza la edición erudita de aquellos materiales íntimos y póstumos, así como la publicación de diarios entregados a los editores por los mismos autores (Girard, 1963). Por tanto, la conciencia de que estos materiales serán leídos algún día marca el estatuto de literariedad de los diarios íntimos desde comienzos del siglo XX, sea como decisión, sea como posibilidad incierta, y se añade a los motivos de literaturización de esta forma de escritura, que se ve a sí misma también como forma de lectura, junto a la radicalidad expresiva y la ficción hermenéutica. Es sin duda lo que se plantea Juan Larrea, al anotar, en julio de 1931, su decisión de que el diario que llevaba algún día, cuando les llegase el momento todavía indistinguible, sería publicado, ya que «he empezado a percibir cómo gran parte de mi vida, si no toda, tiende hacia algo que hasta ayer me era subconsciente. Hacia algo que ha de servir de clave y justificación a todo o parte del edificio construido por las idas y venidas de mi vida. Hacia la publicación de estas notas desbarajustadas empezadas a escribir con un fin de única utilidad personal, con objeto de no olvidar, fallándome como me fallaba la memoria, los puntos de apoyo que me han servido de guías y sostenes a través de mi crisis [...]. Lo importante es que me di cuenta de que [...] todos los antecedentes, los cabos sueltos de mi pasado inmediato encontraban su nudo en la publicación de estas notas. En una palabra, que todas las fuerzas ocultas irrumpieron de un golpe en mi inconsciente, que vio y comprendió que acaso la única justificación en el orden del pensamiento que me devolviera íntegra sin reservas la energía vital, la alegría, la seguridad y la confianza en mí mismo y en el universo, sería la publicación de estas notas» (Larrea, 1990: 28-29).

Por otro lado, la reescritura, buscando el enunciado más cuidado, puede desplazar el conjunto del texto del presente que lo originó y arrastrarlo hacia el presente de la reescritura, que puede constituir un nuevo diario si este proceso no borra sus infinitas huellas en su constitución, lo cual requeriría también una decisión y una determinación al respecto. Todo ello, además, puede darse calidoscópicamente en un mismo haz de anotaciones; de hecho, es improbable que exista un diario estrictamente enunciado según una sola de las posibilidades, lo cual convertiría este obrar en una obra, esta apertura de escritura en un proyecto ya cerrado en el momento de concebirse. La cuestión, así pues, resulta indecidible, y reclama una reflexión no solo para cada diarista, sino incluso para cada página de diario, en sus relaciones con cualquier otra textura genérica: la irrupción del ensayo, de la poesía, del relato, 
de la crítica literaria, etc., en el diario no son, al contrario de lo que podría pensarse, muestras de inconsistencia de su escritura, sino todo lo contrario, ya que, como señala Barthes (1992: 379-380), la posibilidad de un diario pasa por trabajarlo hasta la muerte, hasta el extremo de la más extrema fatiga, como un texto casi imposible, y al final del trabajo es muy posible que el diario así escrito no se parezca en absoluto a un diario. Se trata de una situación, en definitiva, simétrica a la experimentada por la novela en sus relaciones con la autobiografía; la novela ha tenido que deshacer su forma para dar cuenta de la crisis de sus personajes, y haciéndose cargo de la disolución de sus protagonistas, mostrándola, haciéndole frente, se ha quedado sin atributos, se ha vuelto ensayística y autobiográfica para reinventarse como novela. La gran tragedia que acecha toda reflexión sobre diarios es que solamente puede plantearse respecto a lo que intuye común a todo diarista, en tanto que actitud de escritura, y que cada escritor concretará en una poética del diario que se agotará en él mismo, pero modificará la autopercepción de los que le sigan, y la concretización del acto y actitud de lectura del género, y desde esta perspectiva también modificará las confianzas y esperanzas depositadas en esta forma de escritura. La única manera de enfrentarse a este abismamiento, aunque sea de manera precaria y provisional, es la publicación, en tanto que interrupción que estabiliza momentáneamente el proceso, como rastro legible de una interrupción. Si esta reescritura reelabora los diarios como documento para confeccionar una autobiografía, entendida por el escritor como manera de relacionarse con la idea de posteridad, o como lo que Pla llamó literatura contra el olvido, si esta base para unas futuras memorias llega a plantearse y conseguirse, ya sería otra cuestión; el cuaderno mágico que propuso Sigmund Freud (1988: 2809-2811) siempre esconde páginas traspapeladas de más, no de menos; sobre todo porque era un cuaderno sin páginas. O de una sola página infinita, como también la posibilidad de que esta reescritura genere una novela, ya que desde Proust, Joyce, Musil, Pessoa y Kafka la novela no se opone a la autobiografía; la época de los diarios es la época de la disolución de las fronteras entre géneros, y la actual definición de escritura y lectura no opone excluyentemente escritura novelística y autobiográfica. La escritura, que ya no puede no ser autobiográfica, no puede no ser novelística; la vida es narración, es narrarse.

El hecho de que los diarios relaten también la historia de su propia escritura establece su frontera, desde donde se rescatan los acontecimientos vividos para acabar de vivirlos. Fundamentalmente, el diario establecería una oposición con las memorias no porque se escriba en el presente, sino también con el presente. Así es como el escritor de diarios entrelaza la continuidad y la discontinuidad de la vida, siempre recomenzada, cada día enfrentada a su imposibilidad de convertirse en obra porque su manera de ser es un obrar. El diario se encuentra en tensión entre la evidencia que el escritor no puede sino llevar el diario de la obra que no escribe (Blanchot, 1992: 211) y constituir el diario de la escritura de un diario (Rousset, 1986: 155). En el diario, la relación entre las palabras y los días se hace febril, lo que resulta fundamental para entender que el diario puede llegar a ser el diario de la escritura de un diario, pero nunca como tema, sino como acontecer que se cuenta sin acontecimiento. Afirma Blanchot (1955: 25) que el escritor de diarios intenta recordar quién es cuando no escribe, lo cual solo puede conseguirse desde una trágica conciencia de la posibilidad de vivir. Pero todavía resulta más terrible 
esta idea blanchotiana si se desarrolla: el escritor de diarios, más que intentar recordar quién es cuando no escribe, trata de no olvidarlo, puesto que (en) la escritura (ya) se entrega al olvido.

Así, radicalizando las esperanzas depositadas en su palabra, aquello que es cuando no escribe queda transformado por el hecho de ser escribiendo. En el diario, todo cuanto el escritor puede ser cuenta solo con la garantía de cumplimiento de la palabra que va a escribir inmediatamente. Como en cualquier otra escritura autobiográfica, el individuo es imaginado, transforma a cada palabra no solo lo vivido, sino sobre todo lo que es vivido y lo por vivir, aunque sea como posteridad de papel. Pero el momento especular de la escritura autobiográfica (de Man, 1984: 71) es en el diario más bien movimiento especular, un movimiento que se sabe a sí mismo insuficiente pero ineludible; un movimiento que sabe que toda su retórica será insuficiente para realizar un esfuerzo de comprensión del yo, pero que expresa esta imposibilidad cada día y que, precisamente por ello, realizará una nueva tentativa cada día, en cada anotación: el diario es un movimiento sin otro pasado que su propio movimiento. El diario desfigura lo que todavía no es, para hacer viable que sea. Movimiento sin sueño, figura insomne, desfigura lo todavía no figurado; como diría Vallejo, todaviíza su figuración. El diario vela la lejanía de la muerte, por cercana que pueda estar; vela no la muerte, sino su distancia, siempre inminente. Por eso el diario recoge, sobre todo en la época contemporánea, las formas de destrucción de la vida cotidiana, y de la destrucción interior extrae su construcción.

Como escribía Kafka el 16 de enero de 1922, la auto-observación no deja descansar una sola idea: «la observación de sí mismo, observación que no deja tranquila a ninguna idea, las persigue a todas hasta sacarlas a la luz, para luego ella misma ser a su vez perseguida, en cuanto idea, por una nueva observación de sí mismo» Y se trata, según Kafka de una persecución que toma una dirección de apartamiento de la sociedad. «La soledad, que en su mayor parte me ha venido impuesta desde siempre, pero que en parte ha sido buscada por mí -pero que otra cosa sino imposición era también eso-, esa soledad se vuelve ahora completamente inequívoca y llega a su extremo» (Kafka, 2000: 659).

Desde y hacia esta soledad, frontera última en que, siguiendo a Kafka, «toda esta literatura es un asalto a la frontera», el escritor de diarios sabe que la palabra que escribe puede ser su última palabra.

El escritor de diarios escribe en nombre de una araña.

Buenos Aires, agosto de 1998-Barcelona, octubre de 1999

\section{Bibliografía citada}

BARTHES, Roland (1992): «Deliberación», en Lo obvio y lo obtuso. Imágenes, gestos, voces. [L'obvie et l'obtus. Essais critiques III (1982)]. Trad. cast. César Fernández Medrano. Barcelona, Paidós. BAUDElaIRE, Charles (1996): Salones y otros escritos sobre arte. Trad. cast. Carmen Santos. Madrid, Visor.

BÉJAR, Helena (1989): «Individualismo, privacidad e intimidad: precisiones y andaduras», en Castilla del Pino, Carlos, ed., De la intimidad. Barcelona, Crítica.

BLANCHOT, Maurice (1955): L'Espace littéraire. París, Gallimard. 
(1971): Falsos pasos, [Faux pas (1943)]. Trad. cast. Ana Aibar Guerra. Valencia, Pre-Textos. (1992): El libro que vendrá [Le Livre à venir (1959)]. Trad. cast. Pierre de Place. Caracas, Monte Ávila.

DE MAN, Paul (1984): «Autobiography as De-Facement» [Modern Language Notes, 94 (1979)], en

The Rethoric of Romanticism. Nueva York, Columbia UP.

DIDIER, Béatrice (1976): Le Journal intime. París, Presses Universitaires de France.

FOIX, J. V. (1990): Catalans de 1918 [1 $1^{\mathrm{a}}$ ed. 1965], en Obres Completes IV. Sobre literatura $i$ art. Manuel Carbonell, ed. Barcelona, Edicions 62.

FouCAult Michel (1983): «L'écriture de soi», Corps écrit, 5, pp. 3-23. (1990): Tecnologías del yo. [Technologies of the Self (1988)]. Trad. cast Mercedes Allendesalazar. Barcelona, Paidós.

(1994): Hermenéutica del sujeto. Ed. y trad. Fernando Álvarez-Uría. Madrid, Ediciones de la Piqueta.

FREUD, Sigmund (1988): «El ‘block’ maravilloso» [«Noti über den 'Wunderblock’» (1925)], en Obras completas, vol. 15. Trad. cast. Luis López de Ballesteros. Barcelona, Orbis.

GIRARD, Alain (1963): Le journal intime. París, Presses Universitaires de France.

Gombrowicz, Witold (1999): Dietari (1953-1956). Trad. cat. Anna Rubio y Jerzi Slawormirskij. Barcelona, Edicions 62.

KAFKA, Franz (2000): Diarios. Carta al padre. Trad. cast. Andrés Sánchez Pascual y Juan Parra Contreras; ed. Jordi Llovet. Barcelona, Galaxia Gutenberg.

LARREA, Juan (1990): Orbe. Barcelona, Seix Barral.

MARÍ, Antoni (1995): «La intimitat del llenguatge», en AA. VV., El problema de la realitat. Simulacre, frontera, intimitat. Barcelona, KRTU.

Montaigne, Michel E. de (1962): Ensayos [Essais, 1580-1588-1595]. Trad. cast. Juan G. de Luaces. México, Porrúa.

PLA, Josep (2001): El cuaderno gris [El quadern gris, en Obra completa.1; Barcelona, Destino, 1966]. Trad. cast. Dionisio Ridruejo y Gloria Ros. Barcelona, Destino.

PUÉRTOLAS, Soledad (1989): «Literatura de la intimidad», en CASTILla DEL PINO, Carlos, ed., De la intimidad. Barcelona, Crítica.

Rousset, Jean (1986): Le Lecteur intime. De Balzac au Journal. París, Librarie José Corti.

STAROBINSKI, Jean (1974): «El estilo de la autobiografía», en La relación crítica (Psicoanálisis y literatura) [La relation critique. L'Oeil vivant 2 (1970)]. Trad. cast. Carlos Rodríquez Sanz. Madrid, Taurus-Cuadernos para el Diálogo.

SIMMEL, Georg (1977): Filosofia del dinero [Philosophie des Geldes (1900)]. Trad. cast. Ramón García Cotarelo, Madrid, Instituto de Estudios Políticos.

(1986): El individuo y la libertad. Ensayos de crítica de la cultura [Das Individuum und die Freiheit - Brücke und Tür. Essais des Philosophen zur Geschichte, Religion, Kunst und Gesellschaft (1957)]. Trad. cast. Salvador Mas. Barcelona, Península. 
ZAMBRAnO, María (1987): «Por qué se escribe», Revista de Occidente, 132 (jun. 1934), en Hacia un saber sobre el alma $\left[1^{\mathrm{a}}\right.$ ed. 1950]. Madrid, Alianza.

(1995): «Amo mi exilio» [1989], en Las palabras del regreso. Ed. Mercedes Gómez Blesa, Salamanca, Amarú Ediciones. 